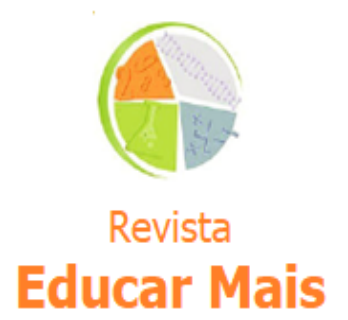

\section{A natureza da Ciência e sua relação com a formação de professores}

Existe consenso entre os pesquisadores da área de Ciências (Carvalho e Gil-Pérez, 2002 e 2011; GilPérez et al., 2011; Carvalho, 2010; Carvalho e Sasseron, 2018) de que, para ensinar com qualidade, é absolutamente necessário conhecer o assunto a ser ensinado. Isso supõe uma ampla gama de conhecimentos, porém podemos constatar que a natureza do conhecimento científico e a história da ciência passam desapercebidas. Verifica-se que os professores da área de Ciências, na sua grande maioria, desconhecem seus propósitos, os processos seguidos pelos cientistas em sua construção, os problemas que levaram à construção do conhecimento científico, como se articularam em corpos coerentes, como evoluíram e quais as dificuldades.

Diversos pesquisadores (Carvalho e Gil-Pérez, 2002 e 2011; Gil-Pérez et al., 2011; Praia et al, 2011; Briccia, 2013; Carvalho e Sasseron, 2010 e 2018) destacaram a importância de os professores de ciências terem uma compreensão adequada dessas questões. Essa importância não corresponde ao tratamento geralmente dado nas Licenciaturas e acaba ocorrendo apenas nos cursos de Pósgraduação. É preciso urgentemente rejeitar a imagem estereotipada e equivocada sobre a Ciência e o Cientista, construída e cristalizada ao longo do tempo, através da cultura e inserida na sociedade.

As pesquisas (Carvalho e Sasseron, 2010; Gil-Pérez et al., 2011; Praia et al, 2011; Martins, 2007) mostraram que a maioria dos professores de ciências geralmente não tem uma visão adequada da natureza da ciência, ou seja, eles têm visões distorcidas que geralmente tem origens no decurso da sua vida escolar na Educação Básica e também no Ensino Superior, incluindo orientação curricular, livros didáticos e postura docente, bem como nas imagens de Ciência e Cientista veiculadas pela mídia. Entre essas concepções podemos citar, baseadas em Gil-Pérez et al. (2011):

i. A concepção empírica indutivista e a teórica. Concepção que destaca o papel "neutro" da observação e da experimentação (não influenciadas por ideias apriorísticas), esquecendo o papel essencial das hipóteses como orientadoras da investigação, assim como dos corpos coerentes de conhecimentos (teorias) disponíveis, que orientam todo o processo.

ii. A visão rígida (algorítmica, exata, infalível, ...). Apresenta-se o "método científico" como um conjunto de etapas a seguir mecanicamente: observação, hipótese, experimentação, resultados, interpretação e conclusões.

iii. A visão aproblemática e ahistórica (portanto, dogmática e fechada): transmitem-se os conhecimentos já elaborados, sem mostrar os problemas que lhe deram origem, qual foi a sua 
evolução, as dificuldades encontradas etc., e não dando igualmente a conhecer as limitações do conhecimento científico atual nem as perspectivas que, entretanto, se abrem.

iv. A visão exclusivamente analítica, que destaca a necessária divisão parcelar dos estudos, o seu carácter limitado, simplificador.

v. A visão acumulativa de crescimento linear dos conhecimentos científicos: o desenvolvimento científico aparece como fruto de um crescimento linear, puramente acumulativo, que ignora as crises e as remodelações profundas.

vi. A visão individualista e elitista da ciência. Os conhecimentos científicos aparecem como obras de gênios isolados, ignorando-se o papel do trabalho coletivo e cooperativo.

vii. A visão que a ciência é socialmente neutra. Esquecem-se as complexas relações entre ciência, tecnologia, sociedade (CTS) e proporciona-se uma imagem deformada dos cientistas como seres intocáveis, fechados em seus laboratórios e alheios as mudanças sociais.

A partir dessas visões da natureza da ciência, podemos deduzir que a maioria dos professores tem posições positivistas muito fortes que são atualmente rejeitadas pela maioria dos filósofos da Ciência (Kuhn, 2011; Bachelard, 1972; Feyrabend, 1977). Obviamente, a imagem da Ciência dos professores está relacionada à Ciência que é mostrada em sala de aula, que é frequentemente dogmática, estática, fechada e acabada. Os professores acreditam que a Ciência é constituída por um conjunto de teorias, leis e princípios que formam um corpo coerente. As aulas, dentro dessa concepção, são fundamentalmente teóricas e baseadas exclusivamente em conteúdo. Nesse sentido, as estratégias de ensino respondem ao chamado modelo transmissão-recepção, onde a aula e o livro didático são os eixos fundamentais.

Considerando essas concepções, acreditamos que é fundamental que os professores de ciências tenham um conhecimento bem estruturado sobre os significados de Ciência e do fazer científico, sendo necessária para isso uma presença significativa dessa temática nos cursos de formação inicial e continuada. Gil-Pérez et al (2011) consideram que o conhecimento sobre a História e Filosofia da Ciência é necessidade fundamental na formação do professor, no sentido de evitar visões distorcidas sobre o fazer científico e permitir uma compreensão mais refinada dos diversos aspectos que envolve o processo de ensino aprendizagem da ciência.

Concordamos com Cavalcanti (2014), por entender que o desconhecimento ou o até mesmo o silêncio com relação às bases epistemológicas na formação dos professores é um ponto que pode levar a uma atuação docente que carrega uma imagem distorcida da ciência e corrobora com o panorama atual, de considerar a ciência algo especial, para pessoas especiais, em lugares especiais e com salários especiais.

Trata-se, pois, de os professores mudarem as suas próprias concepções e representações sobre a própria ciência, relativas à compreensão de problemas científicos mais amplos, que englobam questões como as políticas, sociais, culturais, religiosas e econômicas e que enquadram, assim, as mudanças científicas e mesmo rupturas paradigmáticas a elas inerentes (PRAIA, et al, 2011).

Para Martins (2006) o estudo adequado de alguns episódios históricos também permite perceber o processo social (coletivo) e gradativo da construção do conhecimento, permitindo formar uma visão 
mais concreta e correta da real natureza da ciência, seus procedimentos e suas limitações. Isso contribui para a formação de um espírito crítico e desmistificação do conhecimento científico, sem, no entanto, negar seu valor. A ciência não brota pronta na cabeça de "grandes gênios" (MARTINS, 2006).

Muitas vezes as teorias que aceitamos hoje foram propostas de forma confusa, com muitas falhas, sem possuir base observacional e experimental. Apenas gradualmente as ideias vão sendo aperfeiçoadas, através de debates e críticas, que muitas vezes transformam totalmente os conceitos iniciais (MARTINS, 2006). Esse é um dos aspectos que mostra que a ciência é uma construção coletiva.

O estudo adequado de alguns episódios históricos também permite compreender que a ciência não é o resultado da aplicação de um "método científico" que permita chegar à verdade. Feyerabend (1977) negou a existência "do método", e defendeu um pluralismo metodológico (anarquismo metodológico) e argumentava que a única metodologia capaz de não inibir o progresso científico é o tudo vale, ou seja, desmistificou a ciência e o conhecimento científico. Em oposição às regras racionalistas propôs contra-regras (contra-indução; irracionalismo).

É importante o professor perceber, conforme salienta Gil-Pérez et al. (2011), que a maioria das suas concepções são ingênuas, mal fundamentadas e, afinal, falsas, sobre a natureza das ciências e a sua relação com a sociedade. Alguns concebem a ciência como "a verdade", "aquilo que foi provado", algo imutável, eterno, descoberto por gênios que não podem errar (MARTINS, 2006). Essa é uma visão falsa, já que a ciência muda ao longo do tempo, às vezes de um modo radical, sendo na verdade um conhecimento provisório, construído por seres humanos falíveis e que, por seu esforço comum (social), tendem a aperfeiçoar esse conhecimento, sem nunca possuírem a garantia de poder chegar a algo definitivo (MARTINS, 2006).

A ciência, diferente do que muitos acreditaram, não começa com observações livres de pressupostos teóricos, a partir das quais leis universais são derivadas por indução. As teorias científicas são construções humanas, impregnadas de convicções dos cientistas e seu caráter não é definitivo, muito pelo contrário.

\section{Marcos André Betenps Vaz da Silva ${ }^{1}$ Nelson Luiz Reyes Marques ${ }^{1}$}

\footnotetext{
1 Professor do Programa de Pós-Graduação em Ensino de Ciências e Tecnologias na Educação (PPGCITED) - IFSul - Campus Pelotas - Visconde da Graça.
} 


\section{Referências:}

BACHELARD, Gaston. Conhecimento comum e conhecimento científico. In: Tempo Brasileiro São Paulo, n. 28, p. 47-56, jan-mar 1972.

BRICCIA, V. Sobre a natureza da Ciência e o Ensino. In: CARVALHO, A. M. P. de. (Org.) Ensino de Ciências por Investigação: condições para implementação em sala de aula. São Paulo: Cengage Learning, 2013. p.109-128.

CACHAPUZ, A., GIL-PÉREZ, D., CARVALHO, A. M. P., PRAIA, J. e VILCHES, A. A necessária renovação no Ensino de Ciências. 2. Ed. São Paulo: Cortez, 2011.

CARVAlHo, A. M. e GIL-PÉRES, D. O Saber Fazer do Professor. In: Castro, A. D. e Carvalho, A. M. P. Ensinar a Ensinar. São Paulo: Cengage Learning, 2002.

CARVALHO, A. M. P. e SASSERON, L. H. Ensino e aprendizagem de Física no Ensino Médio e a formação de professores. Estudos Avançados. vol.32 no.94 São Paulo Sept./Dec., 2018.

CARVALHO, A. M. P. e SASSERON, L. H. Abordagens histórico-filosóficas em sala de aula. In: Carvalho, A. M. P. Ensino de Física. São Paulo: Cengage Learning, 2010.

CARVAlho, A. M. P. e GIL-PÉREZ, D. A Formação do Professor de Ciências. 10. Ed. São Paulo: Cortez, 2011.

CAVALCANTI, A. de S. Olhares epistemológicos e a pesquisa educacional na formação de professores de ciências. Educação e Pesquisa, v. 40, n. 4, p. 983-998, 2014

FEYRABEND, P. Contra o método. Rio de Janeiro: Francisco Alves, 1977.

GIL-PÉREZ, D.; FERNANDES, I.; CARRASCOSA, J.; CACHAPUS, A.; PRAIA, J. Superação das visões deformadas da ciência e da tecnologia. In: GIL-PÉREZ, D.; CARVALHO, A. M. P.; CACHAPUS, A.; PRAIA, J.; VILCHES, A. A necessária renovação do ensino das Ciências. São Paulo: Cortez, 2011.

KUHN, T. A Estrutura das Revoluções Científicas. São Paulo: Perspectiva, 2011.

MARTINS, R. de A. Introduçao: A História das ciências e seus usos na Educação. In: Silva, Cibelle Celestino. Estudos de História e Filosofia das Ciências. São Paulo: Livraria da Física, 2006.

MARTINS, A. F. P. História e filosofia da ciência no ensino: há muitas pedras nesse caminho. Caderno Brasileiro de Ensino de Física, v. 24, n. 1: p. 112-131, abr. 2007.

PRAIA, J.; CACHAPUZ, A. e GIL-PÉREZ, D. Problema, teoria e observação em Ciências: para uma orientação Epistemológica da Educação em Ciências. In: GIL-PÉREZ, D.; CARVALHO, A. M. P.; CACHAPUS, A.; PRAIA, J.; VILCHES, A. A necessária renovação do ensino das Ciências. São Paulo: Cortez, 2011. 